\title{
Kurzmitteilungen
}

\section{Riehen, Auf der Bischoffhöhe 13, 1994/12}

Urs Leuzinger

Während der routinemässigen Baustellenüberwachung konnten im Aushub für einen Einfamilienhaus-Neubau zwei Silexartefakte geborgen werden ${ }^{1}$. Eine Untersuchung der Grubenprofile erbrachte leider keinerlei Befunde oder weitere Funde. Bei den Artefakten handelt es sich um einen Kortexabschlag aus gelbem Silex mit wenigen Randretuschen im distalen Bereich (1) sowie um einen länglichen Abschlag aus gelbem Silex (2).

1 Kortexabschlag aus hellgelbem, schwach gebändertem Silex Die Knollenrinde ist bergfrisch. Das Stück trägt distal und vereinzelt entlang der linken Kante einige Randretuschen. L. 62 mm, B. 39 mm, Dm 12 mm. Inv.-Nr. 1994/12.1.

2 Langschmaler Abschlag aus hellgelbem Silex, vereinzelt Spuren von unverollter Knollenrinde. Das Exemplar besitzt einen glatten Schlagflächenrest und trägt deutliche Spuren von dorsaler Reduktion. L. 32 mm, B. 13 mm, Dm 7 mm. Inv.-Nr. 1994/12.2

Diese beiden Fundstücke stehen im Zusammenhang mit der neolithischen Freilandstation unmittelbar neben der Baustelle (Abb. 1: Raster).

Die Artefakte der Fundpunkte Auf der Bischoffhöhe/ Oberfeld (1988/38), Auf der Bischoffhöhe 9 (1991/29),
Auf der Bischoffhöhe 11 (1990/50), Auf der Bischoffhöhe 13 (1994/12) und Auf der Bischoffhöhe 35 (1984/ 18) stammen wohl alle von ein und derselben Station. Das Inventar sämtlicher Funde obgenannter Fundstellen umfasst inzwischen 183 Steinartefakte, darunter zahlreiche Geräte wie ein Steinbeil, eine Pfeilspitze, vier Kratzer, neun Bohrer (davon eine Dickenbännlispitze), drei retuschierte Klingen und 13 retuschierte Abschläge, ferner drei prähistorische Keramikfragmente.

Das Fundensemble datiert in die Jungsteinzeit, wobei eine genauere chronologische Aufgliederung mangels charakteristischer Keramikfunde leider noch nicht möglich ist.

\section{Anmerkung}

Wir danken dem Finder H.J. Leuzinger für die Fundmeldung. Sachbearbeiter: Urs Leuzinger.

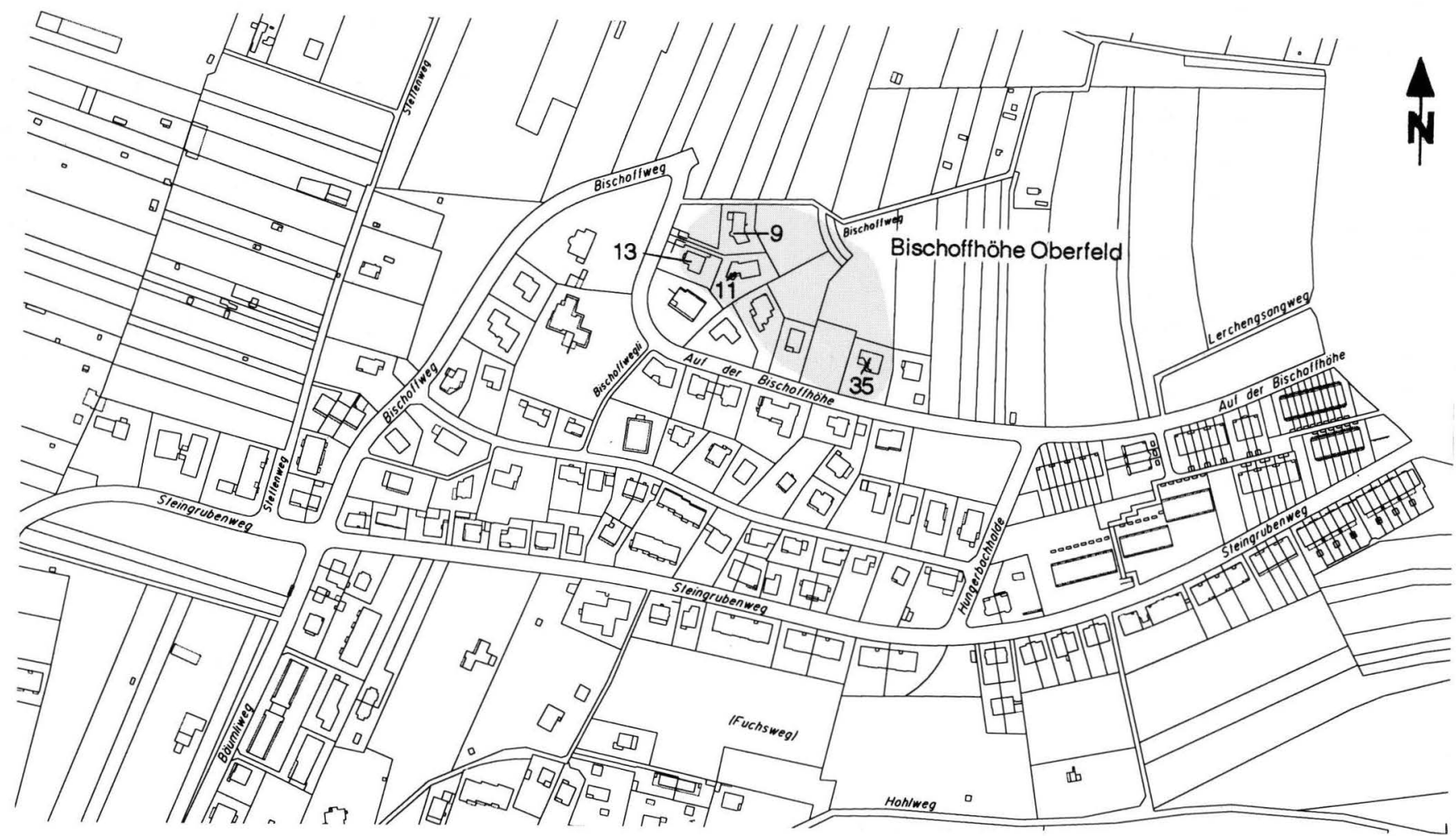

Abb. 1. Riehen, Auf der Bischoffhöhe. Situationsplan. - Massstab 1:5000. 